\title{
ВЛИЯНИЕ МЕТОДА СИНТЕЗА СЛОИСТЫХ ДВОЙНЫХ ГИДРОКСИДОВ НА ИХ ФАЗОВЫЙ СОСТАВ И МАГНЕТИЗМ
}

\author{
(C) 2020 г. О. В. Нестройная ${ }^{1}$, И. Г. Рыльцова ${ }^{1}$, М. Н. Япрынцев ${ }^{1}$, О. Е. Лебедева ${ }^{1, ~ * ~}$ \\ ${ }^{1}$ Белгородский государственный национальный исследовательский университет, \\ ул. Победы, 85, Белгород, 308015 Россия \\ *e-mail: OLebedeva@bsu.edu.ru \\ Поступила в редакцию 26.08.2019 г. \\ После доработки 19.12.2019 г. \\ Принята к публикации 23.01.2020 г.
}

\begin{abstract}
Ряд тетраметаллических слоистых двойных гидроксидов, содержащих магний и кобальт в положениях двухзарядных катионов в структуре бруситоподобных слоев, а алюминий и железо - в положениях трехзарядных катионов, синтезировали с использованием трех различных методов: соосаждения, микроволнового и гидротермального синтезов. В качестве осадителя использован раствор гидроксида натрия. Показано, что при синтезе любым из указанных методов формируются хорошо окристаллизованный гидроталькитоподобный слоистый гидроксид и примесная фаза. Сделано заключение, что именно примесная фаза обусловливает магнетизм образцов. Наиболее вероятно, этой фазой является шпинель $\mathrm{CoFe}_{2} \mathrm{O}_{4}$.
\end{abstract}

Ключевые слова: слоистые двойные гидроксиды, кобальт, железо, магнитные свойства, фаза шпинели

DOI: $10.31857 / \mathrm{S} 0002337 \mathrm{X} 20070106$

\section{ВВЕДЕНИЕ}

Слоистые двойные гидроксиды (СДГ) или гидроталькитоподобные соединения - это основные соли со специфической слоистой структурой. Общая формула данного класса соединений $-\left[\mathrm{M}_{1-x}^{2+} \mathrm{M}_{x}^{3+}(\mathrm{OH})_{2}\right]^{x+}\left[\left(\mathrm{A}^{n-}\right)_{x / n} \cdot m \mathrm{H}_{2} \mathrm{O}\right]$, где $\mathrm{M}^{2+}$ и $\mathrm{M}^{3+}-$ ионы металлов, находящиеся в октаэдрических позициях бруситоподобных слоев, $\mathrm{A}^{n-}-$ анионы, которые компенсируют положительный заряд бруситоподобных слоев [1, 2]. Особенности структуры гидроталькитоподобных соединений и разнообразие катионов, которые могут входить в их состав, обеспечивают специфические ионообменные [3], сорбционные [4, 5], электрические [6] и каталитические [7, 8] свойства СДГ и продуктов их термической деструкции. Привлекает внимание возможность получения СДГ, обладающих магнитными свойствами. Такой эффект наблюдается при одновременном введении в систему катионов железа и кобальта [9].

Ранее методом соосаждения при переменном $\mathrm{pH}$ был синтезирован ряд $\mathrm{MgCo} / \mathrm{AlFe}-\mathrm{CДГ} \mathrm{в} \mathrm{кар-}$ бонатной форме [10]. Было установлено, что только образцы с высоким содержанием железа и кобальта обладают магнитными свойствами, что, вероятнее всего, обусловлено присутствием примесной фазы. Полученные материалы, являющи- еся, по сути дела, композитными, предложено использовать в качестве магнитных сорбентов [11].

Необходимость введения больших количеств железа и кобальта в состав материалов для получения магнитных образцов отрицательно влияет на кристалличность гидроталькитоподобной фазы.

Настоящее исследование направлено на выбор метода и оптимизацию условий синтеза образцов $\mathrm{MgCo} / \mathrm{AlFe}-\mathrm{CДГ,} \mathrm{обладающих} \mathrm{магнетиз-}$ мом при комнатной температуре, при возможно более низком содержании железа и кобальта.

\section{ЭКСПЕРИМЕНТАЛЬНАЯ ЧАСТЬ}

В качестве источников катионов металлов использовали следующие соли: $\mathrm{Mg}\left(\mathrm{NO}_{3}\right)_{2} \cdot 6 \mathrm{H}_{2} \mathrm{O}$, $\mathrm{Co}\left(\mathrm{NO}_{3}\right)_{2} \cdot 6 \mathrm{H}_{2} \mathrm{O}, \mathrm{Al}\left(\mathrm{NO}_{3}\right)_{3} \cdot 9\left(\mathrm{H}_{2} \mathrm{O}\right), \mathrm{Fe}\left(\mathrm{NO}_{3}\right)_{3} \cdot 9 \mathrm{H}_{2} \mathrm{O}$. Все реактивы были квалификации “ч. д. а.”.

Синтез мультиметаллических СДГ состава $\left(\mathrm{Mg}_{1-x} \mathrm{Co}_{x}\right)_{6}\left(\mathrm{Al}_{1-y} \mathrm{Fe}_{y}\right)_{2} \mathrm{NO}_{3} \cdot m \mathrm{H}_{2} \mathrm{O}$ был осуществлен тремя методами: соосаждением при переменном $\mathrm{pH}$, гидротермальным методом и микроволновым методом. Степень замещения магния на кобальт $(x)$ и алюминия на железо $(y)$ варьировали в пределах $10-50$ ат. \%.

Соосаждение осуществляли путем добавления раствора гидроксида натрия к раствору, содержащему необходимые количества солей. Общая 
концентрация ионов металлов в исходной реакционной смеси составляла $1 \mathrm{M}$, а отношение молярной концентрации двухзарядных ионов к концентрации трехзарядных $\left[\mathrm{M}^{2+}\right] /\left[\mathrm{M}^{3+}\right]$ равнялось 3. В процессе синтеза $\mathrm{pH}$ смеси доводили до значения 9-10. Полученные осадки подвергали старению под маточным раствором в течение суток при комнатной температуре и двух суток при $98^{\circ} \mathrm{C}$. Гидротермальный синтез СДГ проводили в автоклаве Autoclave Engineers Parker при температуре $140^{\circ} \mathrm{C}$ и давлении 250-304 кПа в течение 2 суток. Для проведения синтеза под действием микроволнового излучения использовался реактор MARS-6 с временем воздействия микроволнового излучения 10 мин и мощностью 700 Вт. Соотношение компонентов в реакционной смеси и значение рН в случае гидротермального и микроволнового методов синтеза были идентичны описанным выше в методике синтеза соосаждением. В дальнейшем для образцов, полученных методами соосаждения, гидротермальным и микроволновым соответственно используются обозначения $\mathrm{MgCo} X / \mathrm{AlFe} Y-c, \operatorname{MgCo} X / \mathrm{AlFe} Y-h t$ и $\mathrm{MgCo} X / \mathrm{AlFe} Y-m w$, где $X, Y$-атомные доли кобальта и железа (в \%) среди двух- и трехвалентных металлов, задаваемые при синтезе. Продукты осаждения, полученные всеми тремя методами, отделяли от маточного раствора, образцы промывали дистиллированной водой и высушивали при $120^{\circ} \mathrm{C}$.

Рентгенофазовый анализа (РФА) осуществляли на дифрактометре Rigaku (CuK $K_{\alpha}$-излучение) с шагом сканирования по $2 \theta 0.02^{\circ}$. Изучение морфологии синтезированных СДГ проводили методом просвечивающей электронной микроскопии (ПЭМ) на микроскопе JEOL JEM-2100 при рабочем напряжении 200 кВ. Также структуру образцов изучали с использованием дифракции электронов в выбранной области. Элементный состав образцов определяли с использованием растрового электронного микроскопа FEI Quanta 200 3D, оснащенного энергодисперсионным спектрометром (ЭДС) рентгеновского излучения фирмы EDAX при рабочем напряжении 30 кВ. ИК-спектры синтезированных образцов регистрировали с использованием ИК-фурье-спектрометра Shimadzu IR Prestige 21. Регистрацию осуществляли для смеси образцов с бромидом калия. Способность образцов притягиваться магнитом оценивали с использованием магнита в виде параллелепипеда $49 \times 8 \times 4$ мм, сделанного из сплава $\mathrm{Nd}-\mathrm{Fe}-\mathrm{B}$.

\section{РЕЗУЛЬТАТЫ И ОБСУЖДЕНИЕ}

В предыдущих исследованиях [10] при синтезе железокобальтсодержащих СДГ в карбонатной форме в качестве раствора-осадителя нами использовалась смесь гидроксида и карбоната натрия. Последующие эксперименты показали, что осаждение только раствором гидроксида натрия приводит к проявлению магнитных свойств при введении в образцы заметно меньших количеств железа и кобальта. В настоящем исследовании использовали в качестве осадителя гидроксид натрия. В результате преобладающим анионом в образцах СДГ стал нитрат, хотя присутствие карбонатов, источником которых является диоксид углерода из воздуха, также нельзя исключить.

Наличие азота в образцах подтверждается результатами локального рентгеноспектрального анализа (рис. 1). Содержание углерода (в виде карбонатов), возможно, ниже чувствительности метода. В ЭДС-спектрах детектируются все металлы, вводимые при синтезе. Сигналы посторонних элементов отсутствуют. В табл. 1 представлены атомные доли катионов металлов, рассчитанные по данным локального рентгеноспектрального анализа. Из соотношения $\mathrm{M}^{2+} / \mathrm{M}^{3+}$ следует, что в среднем в образцах, полученных соосаждением, содержание двухзарядных катионов больше, чем в образцах, полученных двумя другими методами. Относительно меньшее количество двухзарядных катионов фиксируется в образцах, полученных микроволновым синтезом.

ИК-спектры всех образцов имеют вид, типичный для гидроталькитоподобных соединений (рис. 2), и подтверждают наличие нитрат-анионов в составе синтезированных материалов. В спектрах наблюдается расщепленная полоса в интервале $1370-1515 \mathrm{~cm}^{-1}$. Интенсивный пик $1384 \mathrm{~cm}^{-1}$ обычно относят к антисимметричным валентным колебаниям нитрат-анионов. Появление плеча 1470$1515 \mathrm{~cm}^{-1}$ может быть обусловлено снижением симметрии некоторых нитрат-анионов от $D_{3 h}$ до $C_{2 v}$, т.е. от “свободных" до монодентатных и/или бидентатных [12]. Согласно литературным данным, в области ниже $1000 \mathrm{~cm}^{-1}$ проявляются как полосы, отвечающие деформационным колебаниям нитрат-анионов, так и полосы, относящиеся к колебаниям металл-кислород [12-14]. Полосу низкой интенсивности в области 2250-2375 см-1 обычно относят к атмосферному $\mathrm{CO}_{2}$.

Рентгеновские дифрактограммы образцов, полученных различными методами, приведены на рис. 3-5. Во всех случаях фаза СДГ преобладает на всех дифрактограммах присутствуют семь рефлексов: 003, 006, 009/012, 015, 018, 110 и 113. Наиболее интенсивные и узкие рефлексы наблюдаются на дифрактограммах образцов СДГ, синтезированных в гидротермальных условиях (рис. 4), что свидетельствует о высокой степени кристалличности образцов. Методом Ритвельда были рассчитаны параметры кристаллической решетки СДГ (табл. 1). Параметр $c$ коррелирует с величиной межслоевого расстояния. Расстояния между соседними катионами в бруситоподобном слое характеризуются параметром $a[1,15,16]$. Ожидалось, что введение в структуру бруситоподобных слоев более крупных 


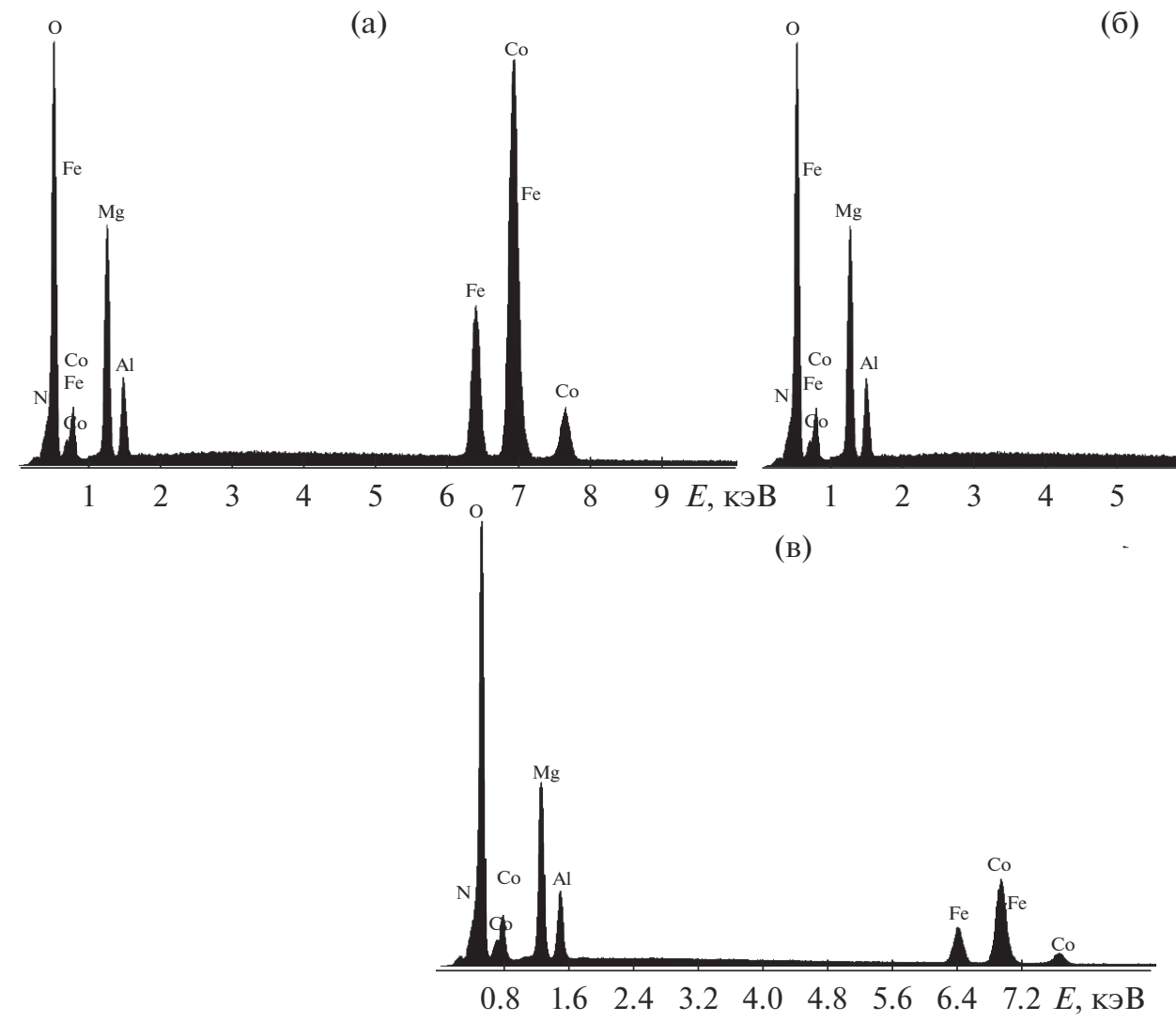

Рис. 1. Результаты локального рентгеноспектрального анализа, полученные с использованием ЭДС, для образцов, синтезированных различными способами: a - MgCo40/AlFe40-c, б - MgCo40/AlFe40- $h t$, в - MgCo40/AlFe40-mw.

по сравнению с магнием и алюминием катионов кобальта и железа должно приводить к увеличению параметра $a$. Действительно, такая тенденция прослеживается в сериях СДГ, синтезированных соосаждением и гидротермальным способом (табл. 1): с ростом содержания железа и кобальта увеличивается значение $a$.

Все синтезированные образцы за исключением MgCo10/AlFe10-mw легко агломерируют под воздействием внешнего магнитного поля и способны притягиваться к магниту. В литературе существуют два противоположных мнения о природе ферромагнетизма кобальт-железных СДГ. В работе [9] показано, что ферромагнетизм при комнатной температуре наблюдался только для образцов, содержащих более 50 ат. \% кобальта и железа в позициях двух- и трехзарядных катионов соответственно. Авторы объясняют ферромагнетизм полученных СДГ сосуществованием ферромагнитных взаимодействий $\mathrm{Co}^{2+}-\mathrm{O}^{2-}-$ $\mathrm{Co}^{2+}$ и антиферромагнитных взаимодействий $\mathrm{Co}^{2+}-\mathrm{O}^{2-}-\mathrm{Fe}^{3+}$ и $\mathrm{Fe}^{3+}-\mathrm{O}^{2-}-\mathrm{Fe}^{3+}$. Однако авторы [17] опровергают это заключение, полагая, что магнетизм при комнатной температуре в подобных системах может быть обусловлен присутствием примесей аморфных фаз, таких как ферригидрит
$(\mathrm{FeOOH})$ или наночастицы оксидов железа (маггемита и магнетита), которые могут не детектироваться с помощью РФА.

Результаты настоящего исследования согласуются с мнением авторов [17]. Большинство синтезированных нами образцов не являются однофазными продуктами. На дифрактограммах образцов присутствуют рефлексы примесной фазы, и есть основания полагать, что магнитные свойства обусловлены ее наличием. Действительно, peфлексы примесной фазы наименее выражены на дифрактограммах образцов, полученных микроволновым синтезом, и синтезированный этим методом образец с низким содержанием железа и кобальта магнитом не притягивается.

Вопрос о природе фазы, придающей образцам магнитные свойства, является дискуссионным. Сравнение дифрактограмм синтезированных образцов со стандартными данными позволяет предположить, что примесная фаза представляет собой $\mathrm{CoFe}_{2} \mathrm{O}_{4}$ (PDF2 00-001-1121). Структура шпинели с отражениями 111, 220, 311 и 511 достаточно отчетливо идентифицирована на дифрактограммах образцов, полученных методом соосаждения. В пользу образования шпинели свидетельствует также тот факт, что трехметаллические СДГ, со- 
Таблица 1. Атомные доли катионов металлов и параметры кристаллической решетки фазы СДГ

\begin{tabular}{|c|c|c|c|c|c|c|c|}
\hline \multirow{2}{*}{ Образец } & \multicolumn{4}{|c|}{ Атомные доли катионов* } & \multirow{2}{*}{$\mathrm{M}^{2+} / \mathrm{M}^{3+}$} & \multirow{2}{*}{$c, \AA$} & \multirow{2}{*}{$a, \AA$} \\
\hline & $\mathrm{Mg}^{2+}$ & $\mathrm{Co}^{2+}$ & $\mathrm{Al}^{3+}$ & $\mathrm{Fe}^{3+}$ & & & \\
\hline $\mathrm{MgCo} 10 / \mathrm{AlFe} 10-c$ & 0.682 & 0.096 & 0.191 & 0.031 & 3.50 & 23.88 & 3.09 \\
\hline $\mathrm{MgCo} 20 / \mathrm{AlFe} 20-c$ & 0.604 & 0.173 & 0.172 & 0.052 & 3.48 & 24.14 & 3.09 \\
\hline $\mathrm{MgCo} 30 / \mathrm{AlFe} 30-c$ & 0.512 & 0.258 & 0.145 & 0.085 & 3.35 & 23.84 & 3.09 \\
\hline $\mathrm{MgCo} 40 / \mathrm{AlFe} 40-c$ & 0.435 & 0.338 & 0.117 & 0.109 & 3.41 & 24.00 & 3.10 \\
\hline $\mathrm{MgCo} 50 / \mathrm{AlFe} 50-c$ & 0.382 & 0.388 & 0.101 & 0.128 & 3.36 & 23.93 & 3.12 \\
\hline $\mathrm{MgCo} 10 / \mathrm{AlFe} 10-h t$ & 0.672 & 0.091 & 0.203 & 0.035 & 3.22 & 23.88 & 3.03 \\
\hline $\mathrm{MgCo} 20 / \mathrm{AlFe} 20-h t$ & 0.595 & 0.168 & 0.186 & 0.051 & 3.21 & 23.97 & 3.09 \\
\hline $\mathrm{MgCo} 30 / \mathrm{AlFe} 30-h t$ & 0.524 & 0.225 & 0.172 & 0.079 & 2.97 & 23.93 & 3.09 \\
\hline $\mathrm{MgCo} 40 / \mathrm{AlFe} 40-h t$ & 0.447 & 0.306 & 0.139 & 0.109 & 3.04 & 24.02 & 3.10 \\
\hline $\mathrm{MgCo} 50 / \mathrm{AlFe} 50-h t$ & 0.366 & 0.382 & 0.126 & 0.127 & 2.97 & 23.94 & 3.12 \\
\hline $\mathrm{MgCo} 10 / \mathrm{AlFe} 10-m w$ & 0.633 & 0.102 & 0.228 & 0.037 & 2.78 & 23.30 & 3.07 \\
\hline $\mathrm{MgCo} 20 / \mathrm{AlFe} 20-m w$ & 0.572 & 0.187 & 0.179 & 0.062 & 3.14 & 24.53 & 3.10 \\
\hline $\mathrm{MgCo} 30 / \mathrm{AlFe} 30-m w$ & 0.486 & 0.264 & 0.161 & 0.089 & 3.00 & 23.83 & 3.08 \\
\hline $\mathrm{MgCo} 40 / \mathrm{AlFe} 40-m w$ & 0.449 & 0.295 & 0.147 & 0.108 & 2.92 & 23.49 & 3.10 \\
\hline $\mathrm{MgCo} 50 / \mathrm{AlFe} 50-m w$ & 0.345 & 0.400 & 0.116 & 0.138 & 2.93 & 23.48 & 3.07 \\
\hline
\end{tabular}

* Рассчитано по данным ЭДС.

держащие только железо или только кобальт, не магнитны.

Известно, что шпинель $\mathrm{CoFe}_{2} \mathrm{O}_{4}$ демонстрирует ферромагнитное поведение при комнатной температуре [18]. Формирование подобных структур в условиях синтеза, описанных в данной работе, воз- можно. Так, авторы [19] сообщают, что при соосаждении раствором гидроксида натрия из водных растворов хлоридов $\mathrm{Co}(\mathrm{II})$ и $\mathrm{Fe}(\mathrm{III})$, взятых в мольном соотношении $1: 2$, при $80^{\circ} \mathrm{C}$ возможно образование $\mathrm{CoFe}_{2} \mathrm{O}_{4}$. В работе [18] описан синтез наночастиц шпинели $\mathrm{CoFe}_{2} \mathrm{O}_{4}$ гидротермальным методом

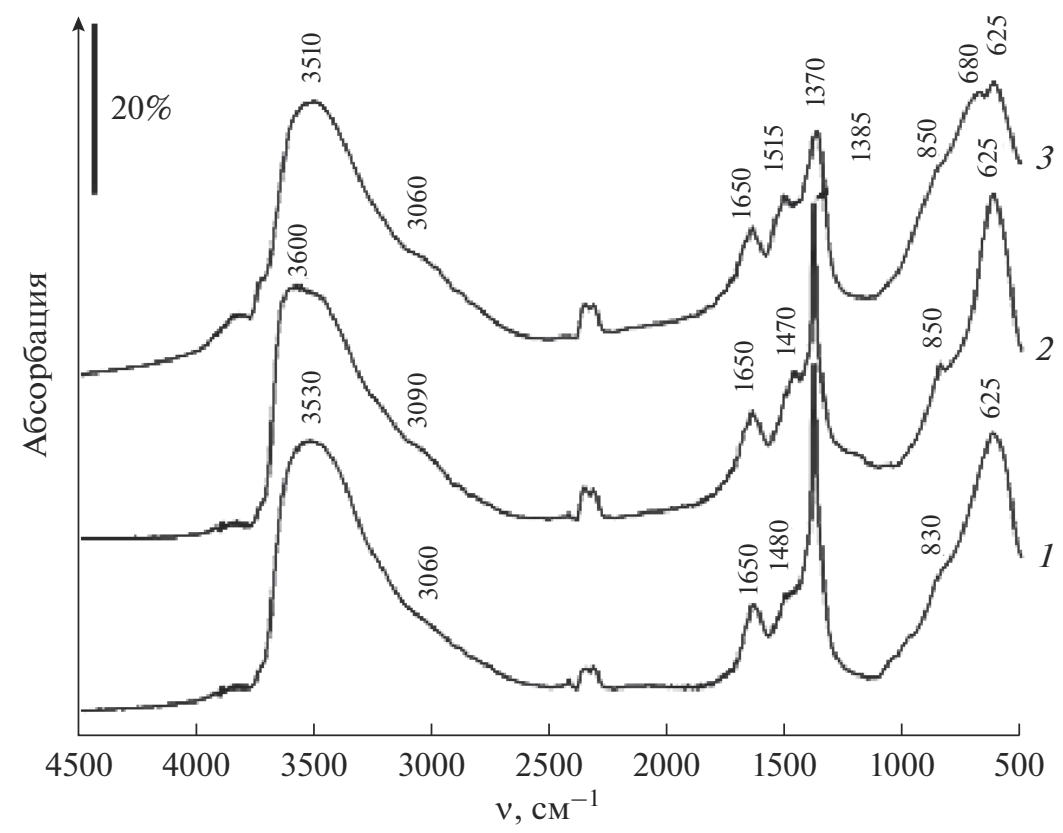

Рис. 2. ИК-спектры образцов, синтезированных различными способами: 1 - MgCo40/AlFe40-c, 2 - MgCo40/AlFe40- $h t$, $3-\mathrm{MgCo} 40 / \mathrm{AlFe} 40-m w$. 


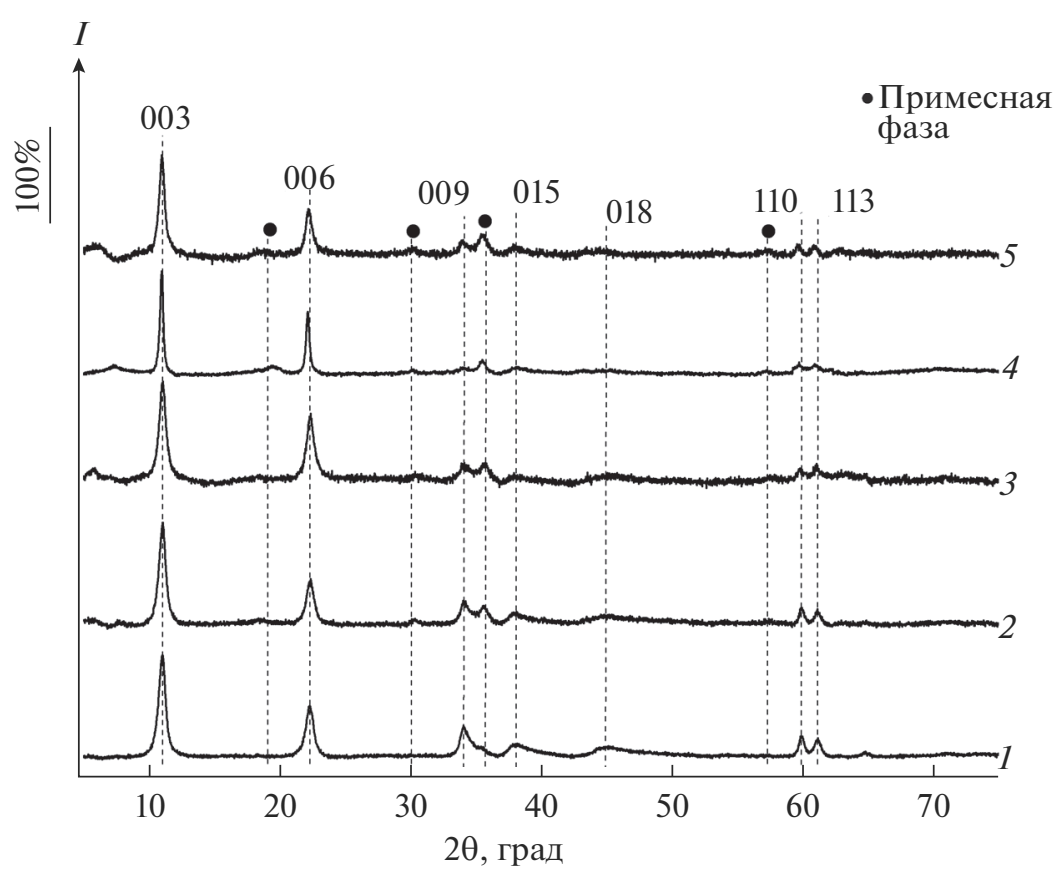

Рис. 3. Рентгеновские порошковые дифрактограммы образцов, синтезированных соосаждением: 1 - MgCo10/AlFe10, 2- MgCo20/AlFe20, 3 - MgCo30/AlFe30, 4- MgCo40/AlFe40, 5 - MgCo50/AlFe50.

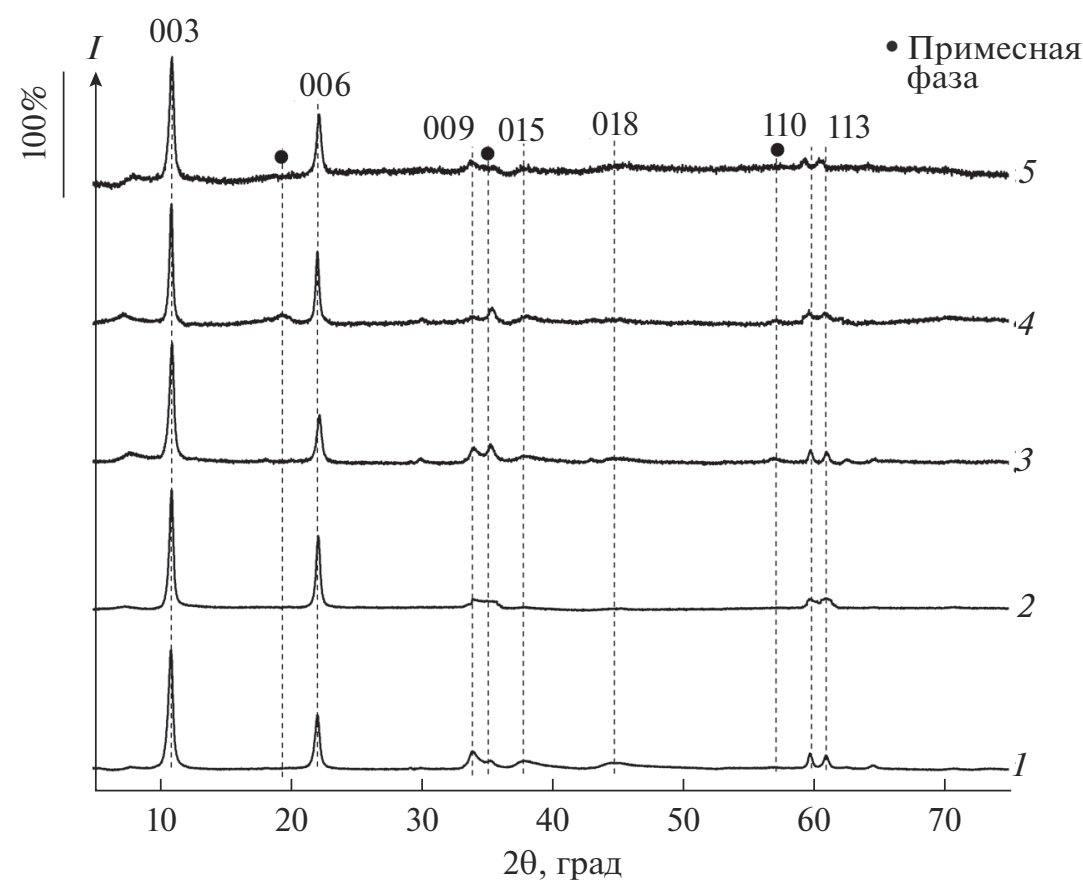

Рис. 4. Рентгеновские порошковые дифрактограммы образцов, полученных гидротермальным синтезом: 1 MgCo10/AlFe 10, 2- MgCo20/AlFe20, 3 - MgCo30/AlFe30, 4 - MgCo40/AlFe40, 5 - MgCo50/AlFe50.

при различных температурах от 90 до $180^{\circ} \mathrm{C}$ с использованием ацетата кобальта(II) и хлорида железа(III) в качестве источников катионов металлов и гидроксида калия в качестве осадителя.

Морфологию синтезированных в настоящей работе образцов оценивали методом ПЭМ. Для образцов, полученных всеми тремя методами, удалось зафиксировать агрегаты пластинчатых частиц, в том числе и гексагональной формы, характерные для СДГ (рис. 6). Наряду с ними наблюдаются кристаллы иной формы. Дифракционная картина выделенной области этой при- 


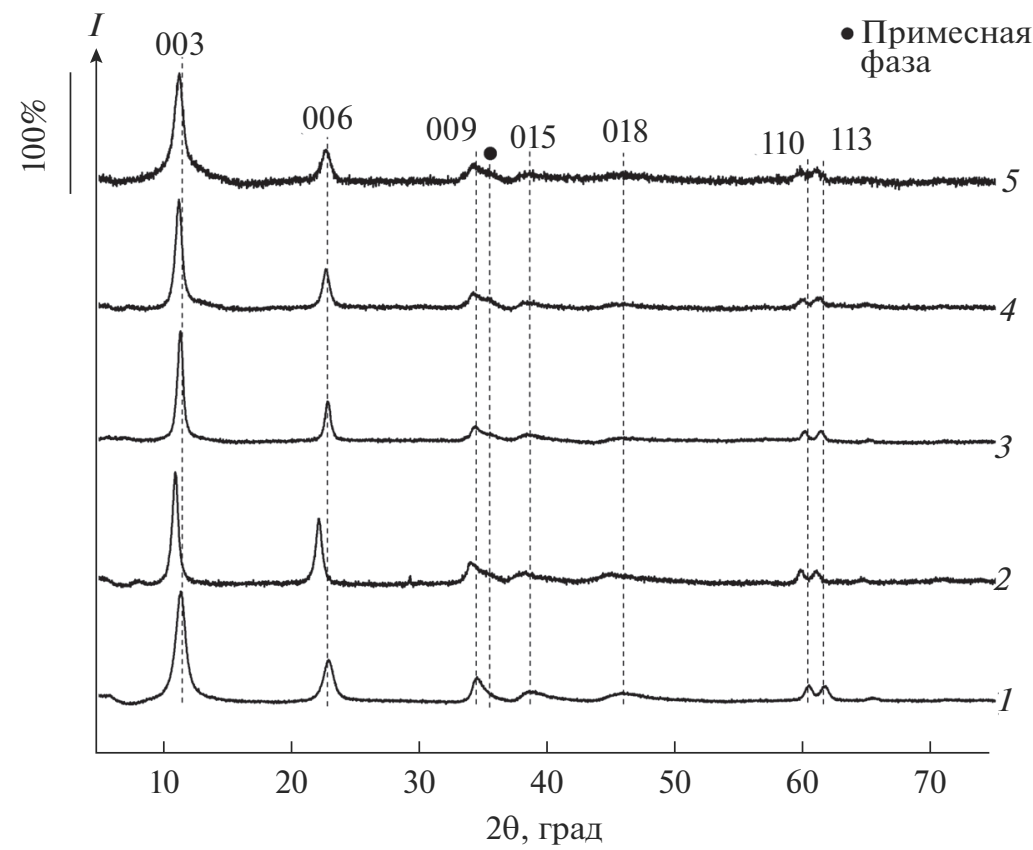

Рис. 5. Рентгеновские порошковые дифрактограммы образцов, полученных микроволновым синтезом: $1-\mathrm{MgCo} 10 / \mathrm{AlFe} 10$, 2- MgCo20/AlFe20, 3 - MgCo30/AlFe30, 4- MgCo40/AlFe40, 5- MgCo50/AlFe50.
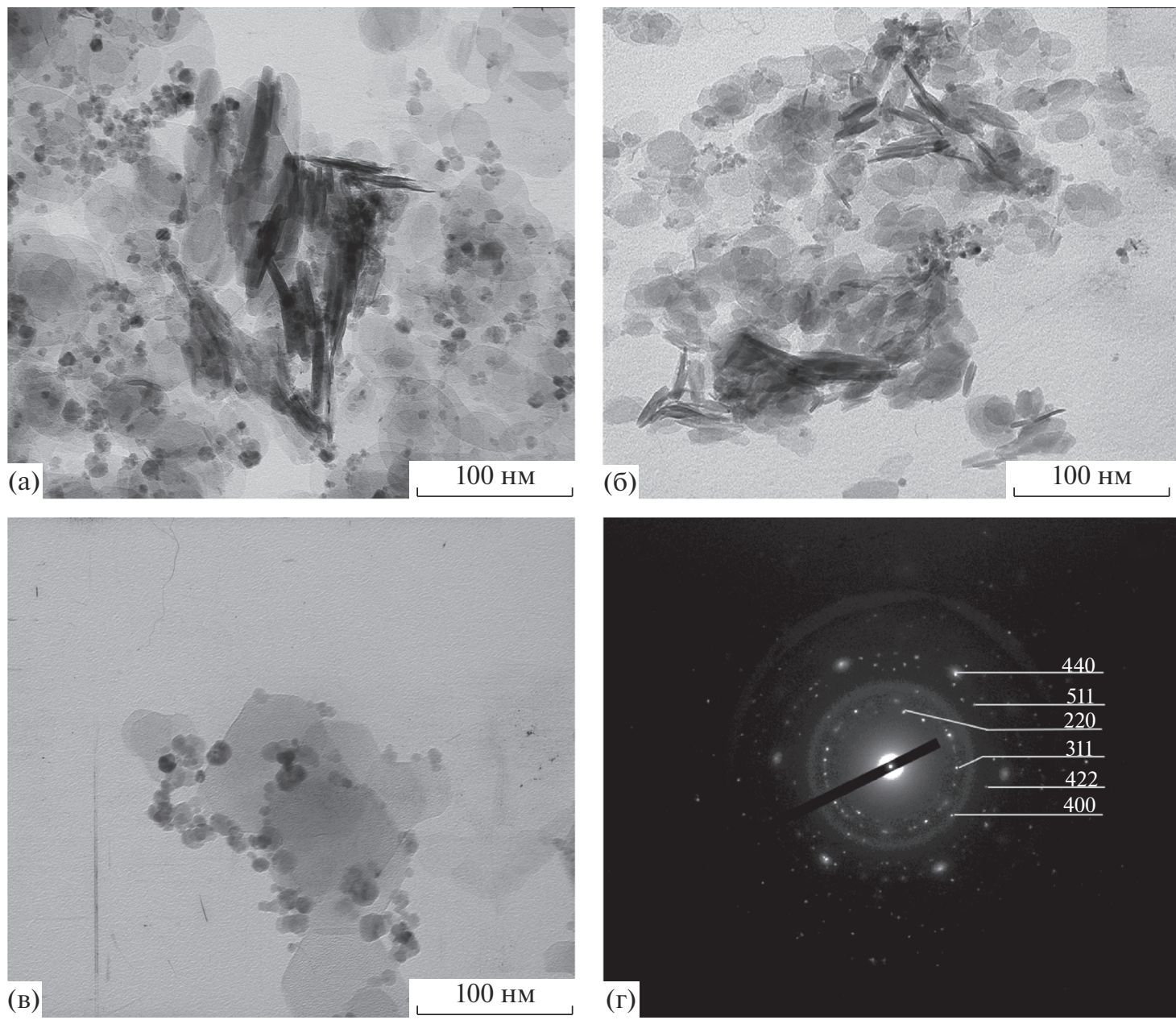

Рис. 6. Снимок ПЭМ образцов, синтезированных различными способами: a - MgCo40/AlFe40-c, б - MgCo40/AlFe40-mw, в - MgCo40/AlFe40- $h t$, г - дифракция в выделенной области для частиц примесной фазы $\left(\mathrm{CoFe}_{2} \mathrm{O}_{4}\right)$. 
месной фазы для образца MgCo40/AlFe40-ht представлена на рис. 6г. Дифракционные кольца были проиндексированы как 220, 311, 400, 422, 511 и 440, что соответствует кубической гранецентрированной решетке шпинели и согласуется с данными РФА. По всей вероятности, осаждение смесью гидроксида и карбоната натрия, практиковавшееся нами в предыдущих исследованиях [10], в меньшей степени способствует формированию шпинельной фазы из-за осаждения основных карбонатов железа и кобальта. Отказ от введения в систему карбонатов в настоящей работе привел к формированию магнитной фазы при более низких содержаниях железа и кобальта.

\section{ЗАКЛЮЧЕНИЕ}

Синтез материалов, содержащих $\mathrm{MgCo} / \mathrm{AlFe}-$ СДГ, возможен как соосаждением, так и гидротермальным или микроволновым методами. При использовании в качестве осадителя гидроксида натрия появление у образцов магнитных свойств происходит при более низком содержании железа и кобальта, чем это наблюдалось при гидроксидно-карбонатном осаждении. Магнитные свойства синтезированных материалов, вероятно, обусловлены присутствием примесной фазы шпинели $\mathrm{CoFe}_{2} \mathrm{O}_{4}$. При одинаковых составах реакционной смеси относительно меньшее количество шпинельной фазы образуется в ходе микроволнового синтеза. Хорошо окристаллизованная фаза СДГ в нитратной форме образуется при использовании всех трех методов синтеза.

\section{БЛАГОДАРНОСТЬ}

Работа выполнена при поддержке РФФИ в рамках гранта № 18-29-12103 мк.

Авторы выражают благодарность ЦКП “Технологии и материалы” НИУ “БелГУ”.

\section{СПИСОК ЛИТЕРАТУРЫ}

1. Cavani F., Trifirò F., Vaccari A. Hydrotalcite-Type Anionic Clays: Preparation, Properties And Applications// Catal. Today. 1991. V. 11. P. 173-301. https://doi.org/10.1016/0920-5861(91)80068-K

2. Третьяков Ю.Д., Елисеев А.А., Лукашин А.В. Синтез функциональных нанокомпозитов на основе твердофазных нанореакторов // Успехи химии. 2004. T. 73. № 9. C. 974-998.

3. Rives V., Arco M., Martín C. Intercalation of Drugs in Layered Double Hydroxides and Their Controlled Release: A Review // Appl. Clay Sci. 2014. V. 88-89. P. 239-269.

https://doi.org/10.1016/j.clay.2013.12.002

4. Liang X., Zang $Y$., Xu Y., Tan X., Hou W., Wang L., Sun Y. Sorption of metal Cations on Layered Double Hydrox- ides // Colloids Surf., A. 2013. V. 433. P. 122-131. https://doi.org/10.1016/j.colsurfa.2013.05.006

5. Goha K.-H., Lima T.-T., Dong Z. Application of Layered Double Hydroxides for Removal of oxyanions: A Review // Water Res. 2008. V. 42. P. 1343-1368. https://doi.org/10.1016/j.watres.2007.10.043

6. Wang W., Zhang N., Shi Z., Ye Z., Gao Q., Zhi M., Hong Z. Preparation of Ni-Al Layered Double Hydroxide Hollow Microspheres for Supercapacitor Electrode // Chem. Eng. J. 2018. V. 338. P. 55-61. https://doi.org/10.1016/j.cej.2018.01.024

7. Fan G., Li F., Evans D.G., Duan X. Catalytic Applications of Layered Double Hydroxides: Recent Advances and Perspectives // Chem. Soc. Rev. 2014. V. 43. P. 7040-7066. https://doi.org/10.1039/C4CS00160E

8. Tanasoi S., Mitran G., Tanchoux N., Cacciaguerra T., Fajula F., Sandulescu I., Tichit D., Marcua I.-C. Transition Metal-containing Mixed Oxides Catalysts Derived from LDH Precursors for Short-Chain Hydrocarbons Oxidation // Appl. Catal., A. 2011. V. 395. P. 78-86. https://doi.org/10.1016/j.apcata.2011.01.028

9. Li Q., Xing L., Lu X., Li N., Mingxiang $X$. Magnetic Properties of $\mathrm{Mg} / \mathrm{Co}(\mathrm{II})-\mathrm{Al} / \mathrm{Fe}($ III) Layered Double Hydroxides // Inorg. Chem. Commun. 2015. V. 52. P. 46-49. https://doi.org/10.1016/j.inoche.2014.12.014

10. Рыльцова И.Г., Нестройная О.В., Лебедева О.Е., Воронцова О.А., Косова Н.И., Курзина И.А. Синтез и изучение новых слоистых двойных гидроксидов магния-кобальта-железа со структурой гидроталькита // Журн. неорган. химии. 2014. Т. 59. № 12. C. $1652-1659$. https://doi.org/10.7868/S0044457X14120216

11. Рыльцова И.Г., Тарасенко Е.А., Нестройная О.В., Лебедева O.E. Сорбционные свойства $\mathrm{MgCo} / \mathrm{AlFe}$ слоистых двойных гидроксидов // Сорбционные и хроматографические процессы. 2019. Т. 19. № 3. C. $305-314$. https://doi.org/10.17308/sorpchrom.2019.19/747

12. Xu Z.P., Zeng H.C. Decomposition Pathways of Hydrotalcite-like Compounds $\mathrm{Mg}_{1-x} \mathrm{Al}_{x}(\mathrm{OH})_{2}\left(\mathrm{NO}_{3}\right)_{x} \cdot n \mathrm{H}_{2} \mathrm{O}$ as a Continuous Function of Nitrate Anions // Chem. Mater. 2001. V. 13. № 12. P. 4564-4572. https://doi.org/10.1021/cm010347g

13. Seftel E.M., Popovici E., Mertens M., Cool P., Vansant E.F. Infrared and Raman Spectroscopic Study of Sn-containing Zn/Al-Layered Double Hydroxides// J. Optoelectron. Adv. Mater. 2008. V. 10. P. 3477-3481.

14. Kloprogge J.T., Wharton D., Hickey L., Frost R.L. Infrared and Raman Study of Interlayer Anions $\mathrm{CO}_{3}^{2-}, \mathrm{NO}_{3}^{-}$, $\mathrm{SO}_{4}^{2-}$ and $\mathrm{CIO}_{4}^{-}$in $\mathrm{Mg} / \mathrm{Al}-\mathrm{Hydrotalcite} / / \mathrm{Am}$. Mineral. 2002. V. 87. P. 623-629. https://doi.org/10.2138/am-2002-5-604

15. Evans D.G., Slade R.C.T. Structural Aspects of Layered Double Hydroxides // Layered Double Hydroxides. Structure and Bonding / Eds. Duan X., Evans D.G. V. 119. Berlin, Heidelberg: Springer, 2005. P. 1-87. https://doi.org/10.1007/430_005

16. Rozov K.B., Berner U., Kulik D.A., Diamond L.W. Solubility and Thermodynamic Properties of Carbonate- 
bearing Hydrotalcite-pyroaurite Solid Solutions with a $3: 1 \mathrm{Mg} /(\mathrm{Al}+\mathrm{Fe})$ Mole Ratio // Clays Clay Miner. 2011. V. 59. № 3. P. 215-232. https://doi.org/10.1346/CCMN.2011.0590301

17. Abellen G., Carrasco J., Coronado E. Room Temperature Magnetism in Layered Double Hydroxides due to Magnetic Nanoparticles // Inorg. Chem. 2013. V. 52. № 14. P. 7828-7830. https://doi.org/10.1021/ic400883k

18. Liu W., Chan Y., Cai J., Leung C., Mak C., Wong K., Zhang F., Wu X., Qi X.D. Understanding the Formation of Ultrafine Spinel $\mathrm{CoFe}_{2} \mathrm{O}_{4}$ Nanoplatelets and Their Magnetic Properties // J. Appl. Phys. 2012. V. 112. P. 104306.

https://doi.org/10.1063/1.4765033

19. Roy P., Manjura H.S., Liba S.I., Choudhury S. Investigation of Various Magnetic Features of Spinel Type Cobalt Ferrite $\left(\mathrm{CoFe}_{2} \mathrm{O}_{4}\right)$ Nanoparticles Tuned by Annealing Temperature // AIP Advances. 2018. V. 8. P. 105124.

https://doi.org/10.1063/1.5040890 